\title{
A critical review of the evidence for nurses as information providers to cancer patients
}

\author{
Sotiria Koutsopoulou, Elizabeth DE Papathanassoglou, Maria C Katapodi and Elisabeth I Patiraki
}

Aims. To review evidence on the role of oncology nurses in the provision of information to cancer patients and to delineate evidence-based implications for clinical practice and research.

Background. Provision of information is central for the empowerment of patients to participate in their care. There is not enough evidence regarding the nursing role in the information delivery process in cancer patients.

Design. Descriptive literature review.

Methods. From January 1990-2008, databases searched included Medline, CINAHL, PubMed, CancerLit and the Cochrane Library. Original research articles addressing the role of nurses in information delivery were included. We explored evidence on: (1) the effectiveness of nurses as information providers, (2) the way patients evaluate nurses' input to information delivery, (3) the extent to which nurses contribute to information delivery to cancer patients and (4) the types of information provided by nurses.

Results. The most important findings were: (1) nurses' role as information providers for cancer patients is prominent, especially after the initiation of treatment, (2) specialist nurses are very effective in providing information, (3) no clear evidence exists on how nurses compare with other health-care professionals as information providers and (4) some evidence exists that patients may prefer nurses as information providers at specific times in their treatment and especially in regards to symptom management.

Conclusion. Well-designed studies provide some evidence that nurses are effective as information providers to cancer patients. Specifically, oncology nurses are able to provide information of both high quality and of appropriate quantity and to assist individuals to interpret information provided by others.

Relevance to clinical practice. Oncology nurses should be specifically educated and prepared to offer explicit, practical and timely information and they should be trained in interpersonal communication skills, which will increase their ability to comprehend patient information needs.

Key words: cancer, critical review, information delivery, information provider, nurse, oncology

Accepted for publication: 12 March 2009

\section{Introduction}

Obtaining access to high quality and reliable information regarding their treatment is a top priority for cancer patients
(Meredith et al. 1996, Veronesi et al. 1999). Information is data acquired by cancer patients in any manner (Chelf et al. 2001) and information delivery is a core nursing intervention (Benner 1984). To deal with cancer and its consequences,
Authors: Sotiria Koutsopoulou, MSc, RN, Staff Nurse, Internal Medicine Hellenic Red Cross Hospital; Elizabeth DE Papathanassoglou, MSc, PhD, RN, Assistant Professor, University of Athens School of Nursing, Athens, Hellas, Greece; Maria C Katapodi, PhD, MSN, RN, Assistant Professor, Ann Arbor School of Nursing, University of Michigan, Ann Arbor, MI, USA; Elisabeth I
Patiraki, PhD, RN, Associate Professor, University of Athens School of Nursing, Athens, Hellas, Greece

Correspondence: Elisabeth J Patiraki, Associate Professor, Nursing Faculty, University of Athens, 123 Papadiamantopoulou Street, Athens 11523, Hellas, Greece. Telephone: +30 2107461464.

E-mail: epatiraki@nurs.uoa.gr 
individuals require accurate information, relevant to their situation, which they themselves perceive as important. This type of information may enhance patients' adherence to the prescribed treatment, their sense of control over their disease (Sainio \& Eriksson 2003, Skalla et al. 2004) and, presumably, their clinical outcomes as well (Veronesi et al. 1999). Provision of information is central for the empowerment of patients to participate in and to make informed decisions about their care (Hinds et al. 1995, Chelf et al. 2001, Davison et al. 2003). Additionally, studies by Johnson et al. (1997) and evidence pertinent to the self-regulation theory of coping (Lundberg \& Trichorb 2001), suggest that provision of specific information may enhance patients' well-being and recovery and may decrease their stress (Bilodeau \& Degner 1996, Luker et al. 1996, Harrison et al. 1999, Leydon et al. 2000). This may be especially important for cancer patients since stress has been identified as a significant factor in patients' outcomes (Johnson et al. 1997).

The provision of information to cancer patients constitutes a distinct field of important nursing interventions. Nurses who work in oncology settings may function in several roles, providing expert clinical, educational, emotional and supportive care to cancer patients. However, to enhance this significant aspect of their practice, so as to confidently target desired patient outcomes, nurses need to develop a clear and meaningful definition of their role in information delivery and, subsequently, in patient education and counselling.

However, there is not enough evidence regarding the nursing role in the information delivery process in specific populations of patients, including cancer patients. According to an overview of 176 articles on cancer-related education (Chelf et al. 2001), although physicians were the preferred source of information for patients with cancer, nurses were identified as 'extremely helpful' resources. Patients preferred to obtain information through discussion, which means that interpersonal information providers are especially valuable during the cancer trajectory. Similarly, six other review studies present findings which establish that the role of health care professionals (HCPs) as information providers is a measure of the quality of healthcare services (Mills \& Sullivan 1999, Flanagan \& Holmes 2000, Rees \& Bath 2000, Echlin \& Rees 2002, Semple \& MCGowan 2002, Davies \& Higginson 2003), whereas, Rutten et al. (2005) found that during post-treatment, physicians, nurses and other HCPs become equally important as sources of information.

\section{Aims of the review}

The aim of this literature review is to summarise evidence from qualitative and quantitative research on the provision of information as a nursing intervention implemented for cancer patients. Specifically, we explored evidence on: (1) the extent to which nurses contribute to the information delivery to cancer patients, (2) the effectiveness of nurses as information providers, (3) the way patients evaluate nurses' input to the information delivery and (4) the types of information provided by nurses. This is the first review which focuses exclusively on nurses' role as information providers, placing a special focus on information provided exclusively to cancer patients. Although the nurse also has an important role in the provision of information and support to these patients' families and significant others, this review focuses only on nurse-patient interactions, since these bear the potential to directly enhance patient outcomes and reduce stress responses.

\section{Methods}

\section{Design}

A descriptive critical review methodology was employed. The study was based on published research from January 19902008.

\section{Search methods}

Articles were selected and reviewed based on the following review questions:

- What is the role of nurses in the provision of information to cancer patients?

- Is there evidence on the effectiveness of oncology nurses as information providers and how do they compare to other HCPs?

- How do cancer patients appraise nurses as information providers?

- What kinds of information do patients require and/or obtain from oncology nurses?

Databases searched included Medline, CINAHL, PubMed, CancerLit and the Cochrane Library. Studies were retrieved by using the following key words in a variety of combinations: 'information provider', 'information delivery', 'information source', 'oncology nurse', 'oncology' and 'cancer'. References of identified studies were also checked for relevancy to the aims of the study.

\section{Search outcome}

Studies were classified as randomised clinical trials, prospective studies, retrospective studies, cross-sectional studies, surveys and qualitative studies. The selection criteria for articles were as follows: 
- Articles published since 1990, as evidence on the role of nurses as information providers was very scarce before this date.

- Studies with an oncology focus.

- Studies investigating the nursing role in the information giving process.

The exclusion criteria were:

- Articles addressing types of information sources other than nurses.

- Articles addressing provision of information to family members.

Articles were assessed and analysed using a two-phase process (Fig. 1). During the first phase, 185 abstracts were examined, focusing on the questions mentioned above. In the second phase, approximately 65 studies were critiqued and graded for quality. Nineteen articles were excluded. The specific exclusion criteria employed at the second phase of selection were:

- Studies expressing opinions on nurses' input rather than research based data.

- Expert's views.

- Clinical audit results.

- Clinical trials of nursing interventions that do not provide results for information delivery, specifically.

The final literature review examined 46 articles: 17 qualitative studies and 28 studies with a quantitative design and 1 study with mixed qualitative and quantitative methodology.

\section{Data extraction and synthesis}

The articles were read and were categorised according to their specific focus (e.g. general nurses' role, specialist nurses' role etc.). Next they were assessed for methodological quality and their attributes were entered into a table that included a crude rating of their methodological quality along with a brief description of potential limitations, the specific population, the research design and the main results. The table was used as a guide for data extraction and synthesis, which was undertaken by the first author and confirmed by the rest of authors. Data were synthesised descriptively, taking into account the specific merits and limitations of each study.

\section{Quality appraisal}

The quality of the studies reviewed was diverse. Investigators have employed various methodologies and in their majority results are based on convenience or purposeful samples, which may have limited the external validity of the studies. All studies retrieved were either quantitative descriptive or qualitative (Tables 1 and 2), therefore, rating of evidence levels could not be performed. Moreover, study-specific
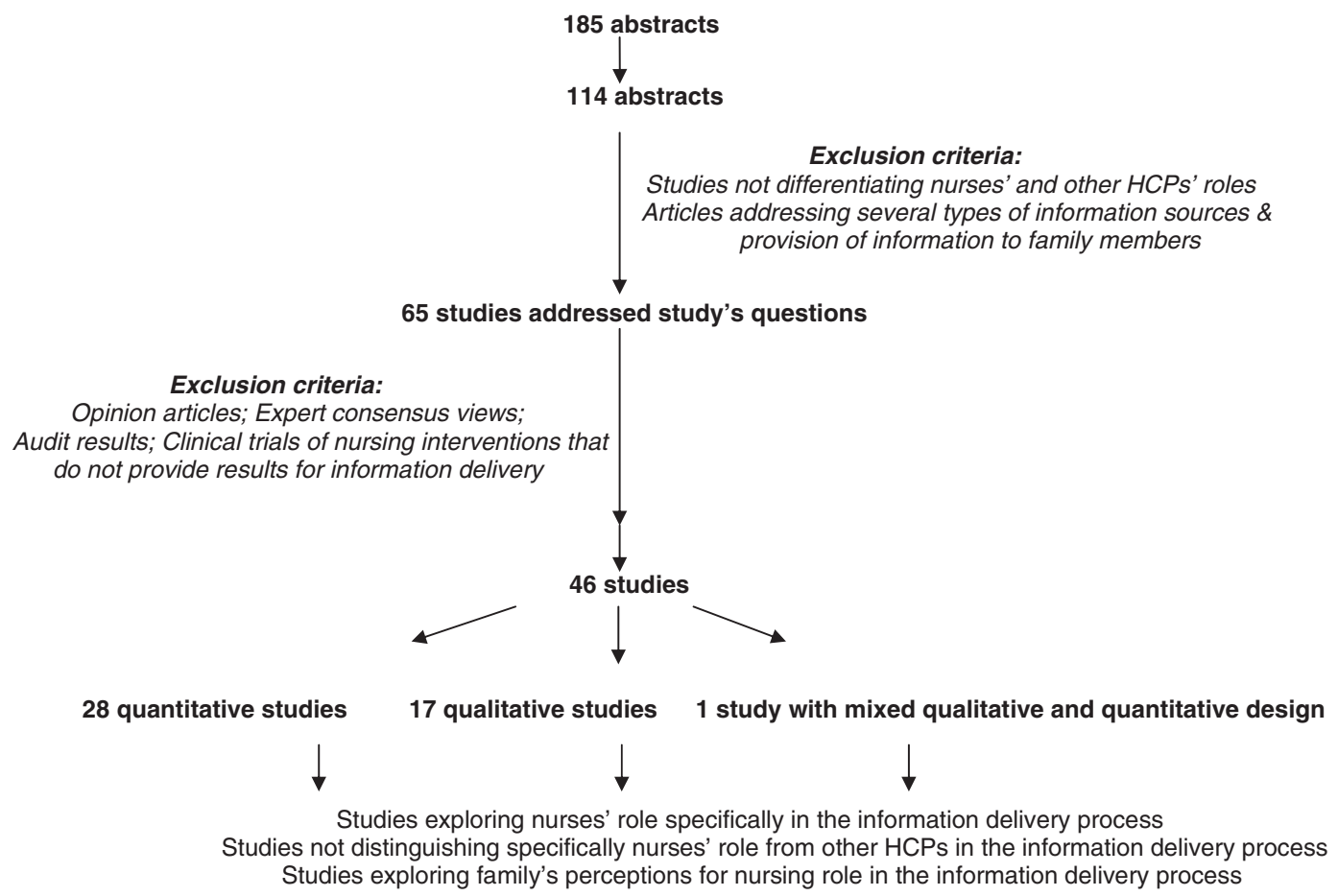

Figure 1 Retrieval and selection process of studies. 
survey-type questionnaires were most commonly used which may have limited the validity of inferences. Nonetheless, since the aim of the review was to critically appraise nurses' input to the information delivery from the patients' perspective and since stringent quality criteria would exclude many studies, all studies which addressed the research questions and complied with the inclusion/exclusion criteria were included. Potential methodological limitations are noted, alongside with the presentation of the results.

\section{Data synthesis}

Results were categorised as those (1) addressing nurses' role specifically, (2) exploring specialist nurses' roles and (3) not distinguishing nurses' role from that of other HCPs. Throughout data synthesis, the nationality of patients was taken into consideration due to potential differences in nurses' roles in different countries.

\section{Results}

\section{Studies exploring nurses' role specifically}

\section{Results referring to nurses in general}

Hinds et al. (1995) interviewed a convenience sample of 83 American patients before and after a full course of radiotherapy. The most often mentioned method of information delivery, either at pre-treatment or at post-treatment, was verbal communication, especially with the physician. However, nurses were perceived as an information source more often at post-treatment. One explanation involved the treatment procedure, since all radiotherapy patients had weekly appointments with a department nurse that allowed them to ask questions. The authors presumed that nurses were in a position to provide patients with timely information, at an individual level. The other explanation was based on the particular content of information that patients needed as treatment progressed, which was increasingly related to the side effects and to family concerns. However, the above are presumptuous.

The results of an ethnographic study, carried out in Denmark, appeared to corroborate the assumption that nurses are seen as sources of information which differs from that delivered by physicians. Specifically, patients with acute myeloid leukaemia sought information primarily by asking nurses and fellow patients (Friis et al. 2003), whereas, they avoided to receive further medical details about their disease and prognosis as a strategy to maintain hope. Rather, they focused on information related to problems affecting everyday life. Moreover, in a qualitative content-analysis study from China (Liu et al. 2006), nurses were seen as the main source of informational support and met patients' needs for knowledge.

Similarly, in a descriptive quantitative study of Thai Buddhist patients undergoing radiation therapy, high levels of satisfaction with nurse-provided information delivery were reported. The results indicated that patients wished oncology nurses to educate them before commencement of therapy, since such information assisted them to prepare mentally, to reduce their anxiety and to understand what to expect (Lundberg \& Trichorb 2001). Most participants believed that nurses were good in providing explanations and that they used simple language. In line with the above, in Canada, Deane and Degner (1998) noted that women who had undergone breast biopsy wanted nurses to provide them with information mainly about the diagnosis of the breast biopsy, because they were too anxious to remember all the information they had received by their physician. These results are consistent with the findings from a Canadian qualitative (Gray et al. 1998) and a French study (Negrier et al. 2007). Sainio and Eriksson (2003), in a study involving 273 Finnish cancer patients, reported that nurses compared to physicians had provided more information to patients, using a variety of methods of oral or written information. Patients felt that nurses provided information understandably, truthfully, willingly and at a suitable amount of time.

The findings of the aforementioned studies suggest that the role of nurses in information delivery is central and that they may provide different types of information and in a different manner compared to physicians. Overall, the studies reviewed above suggest that the majority of cancer patients were able to orientate to the new situation through the information provided by nurses. In general, through specific informational support, patients adapted better to their disease and developed a stronger faith in the future (Lauri \& Sainio 1998). Nonetheless, two phenomenological studies reported that the participants experienced nurses as unavailable or uninvolved in their decision-making (Lacey 2002) and that the role of nurses in providing information was not clearly discernible (Brown et al. 2000). The reason for this discrepancy is unclear; presumably, in-depth interviews may reveal concealed meanings, that is, not only whether information was provided or not, but also patients' perceptions of the willingness and quality of nurses' engagement in the process.

In summary, these results appear to suggest that nurses are perceived as effective and important information providers by cancer patients, especially in relation to the provision of explanations and clarifications on information previously provided by physicians. However, the lack of clarity 


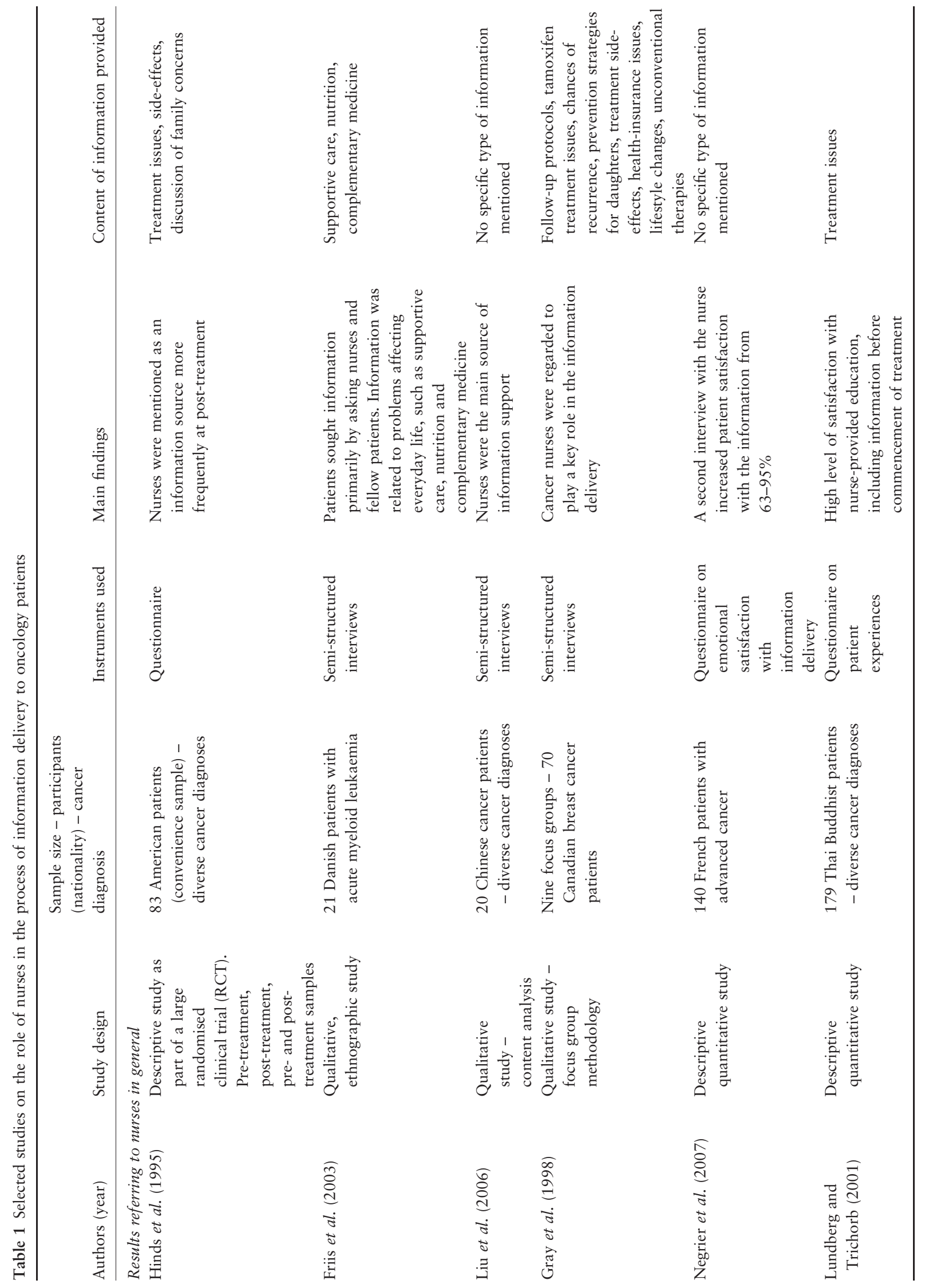




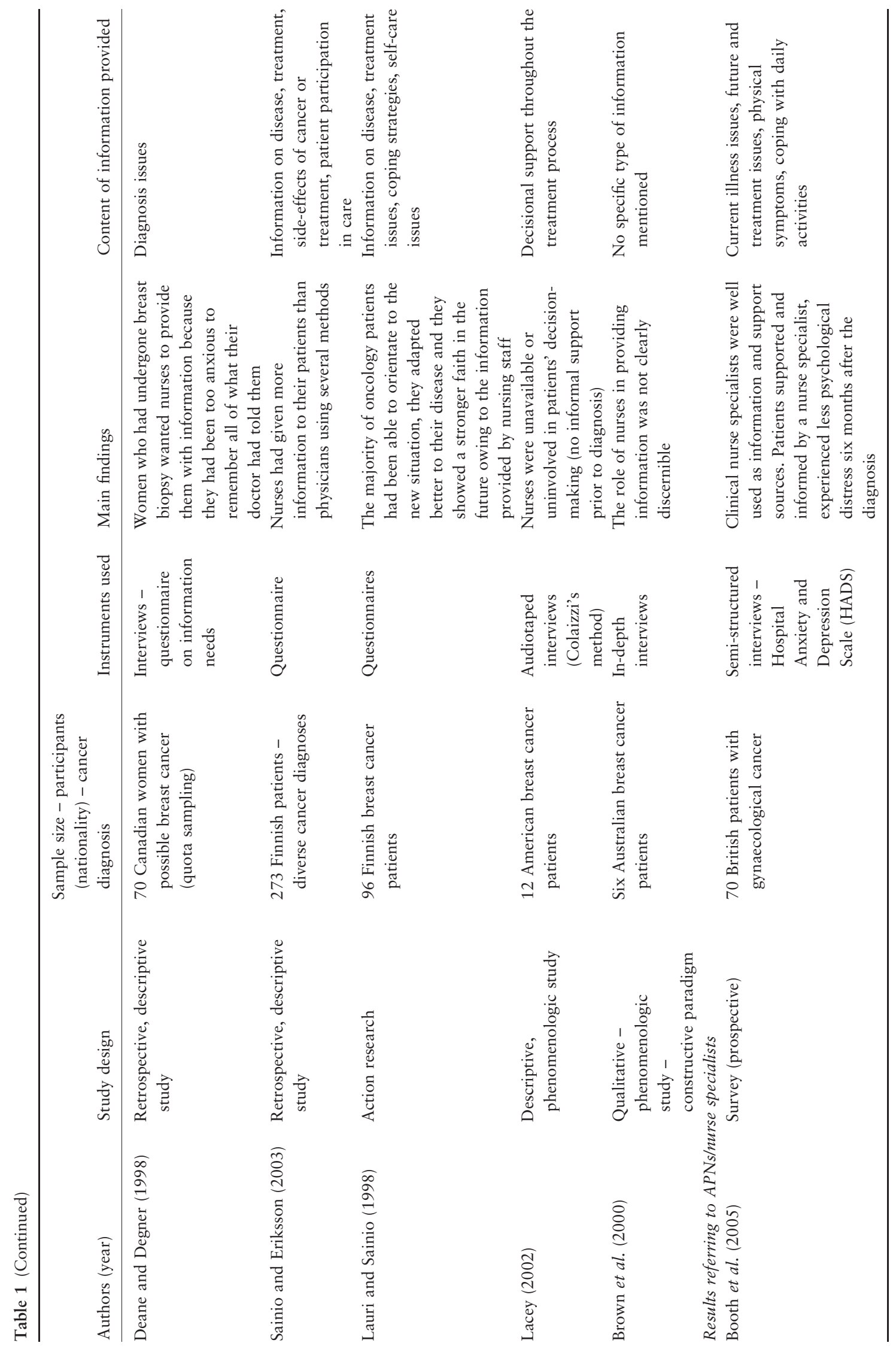




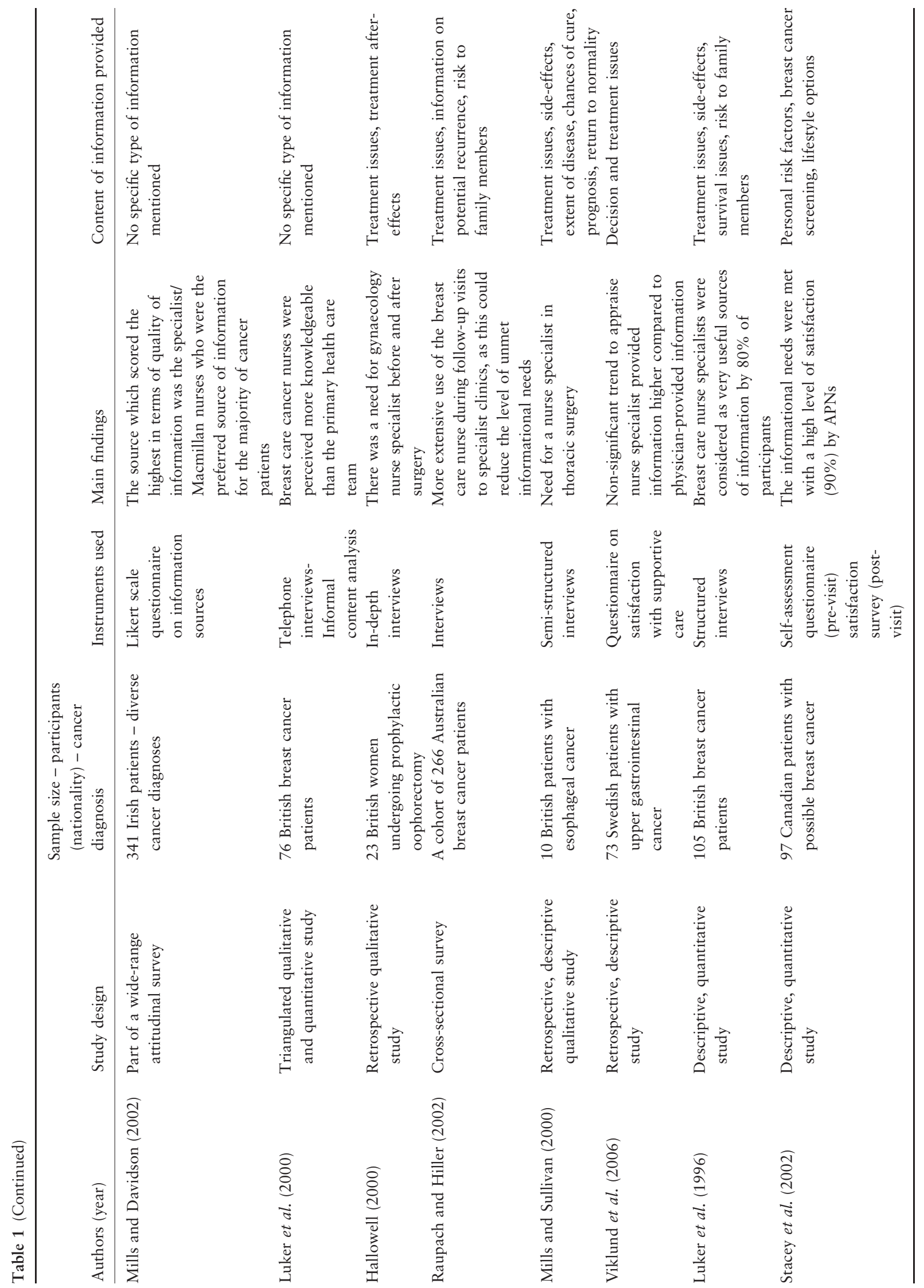




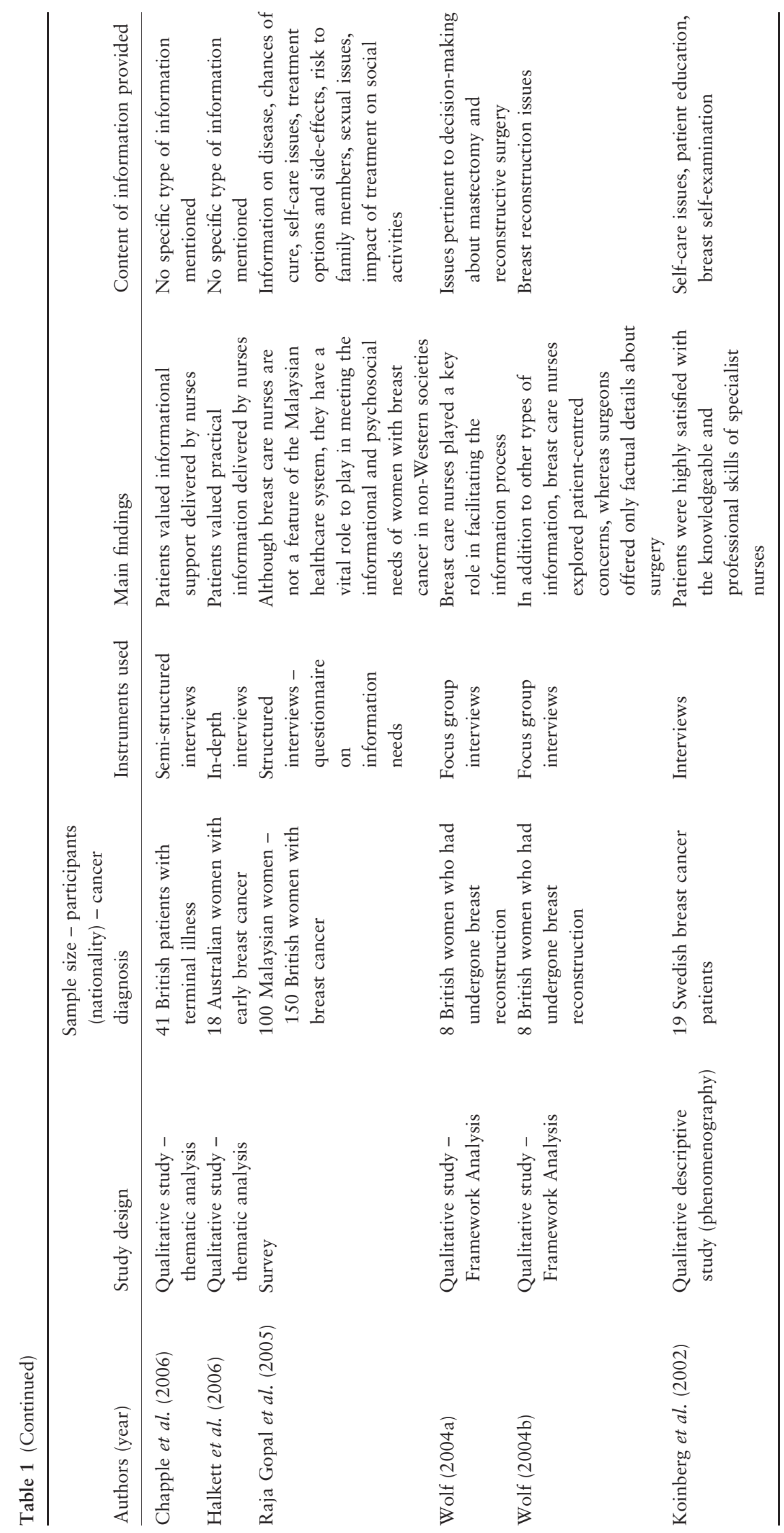




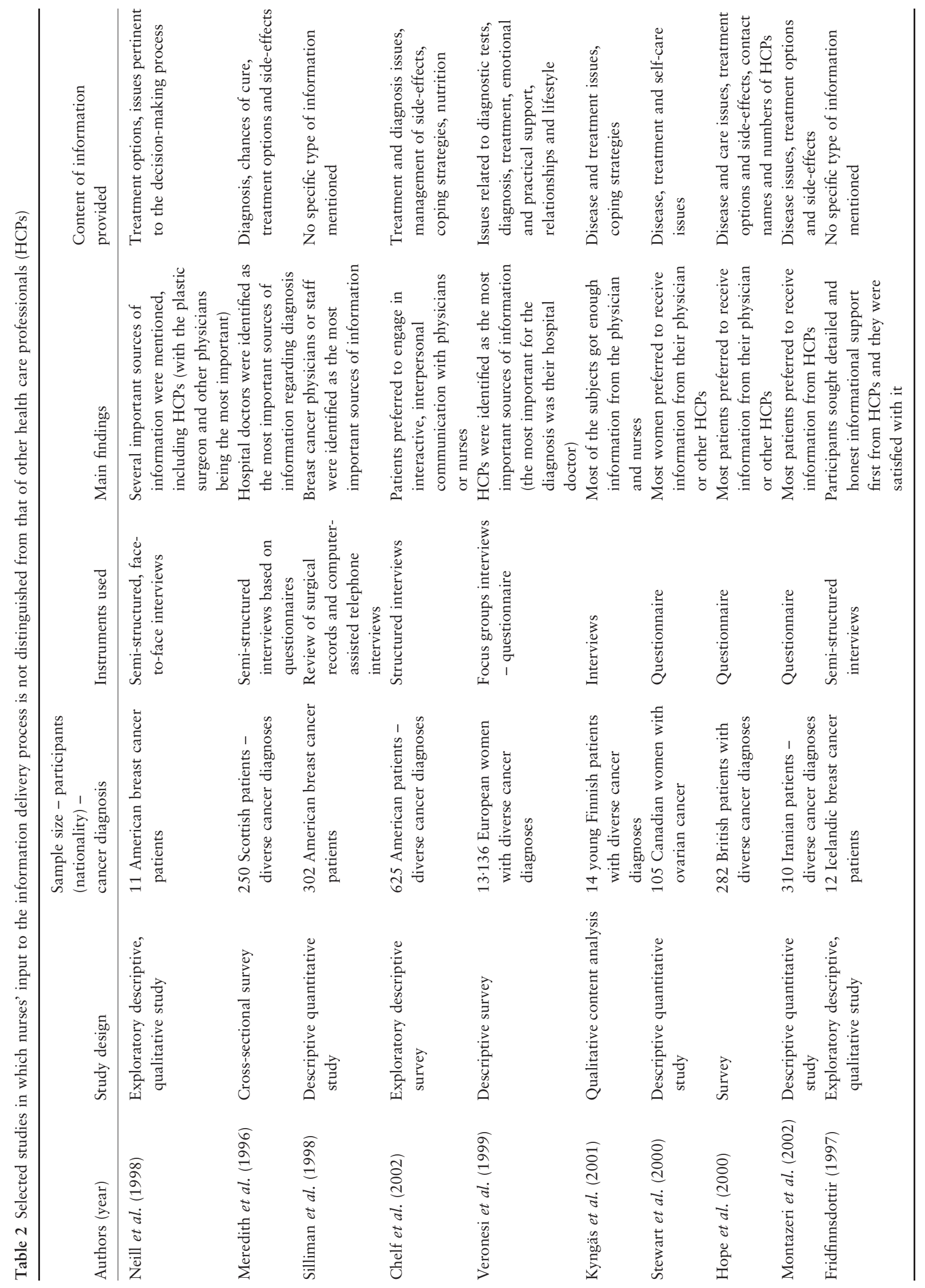




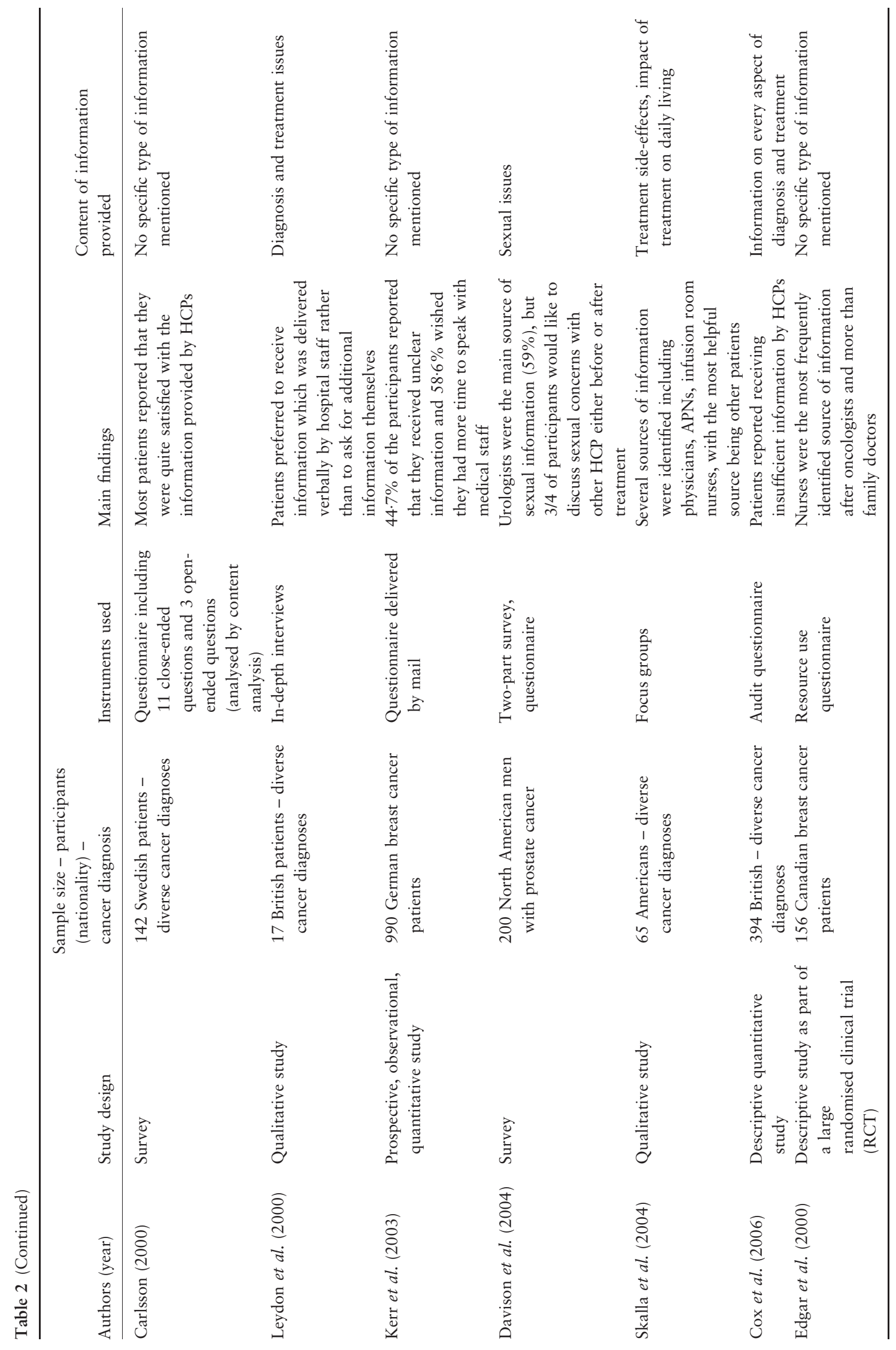




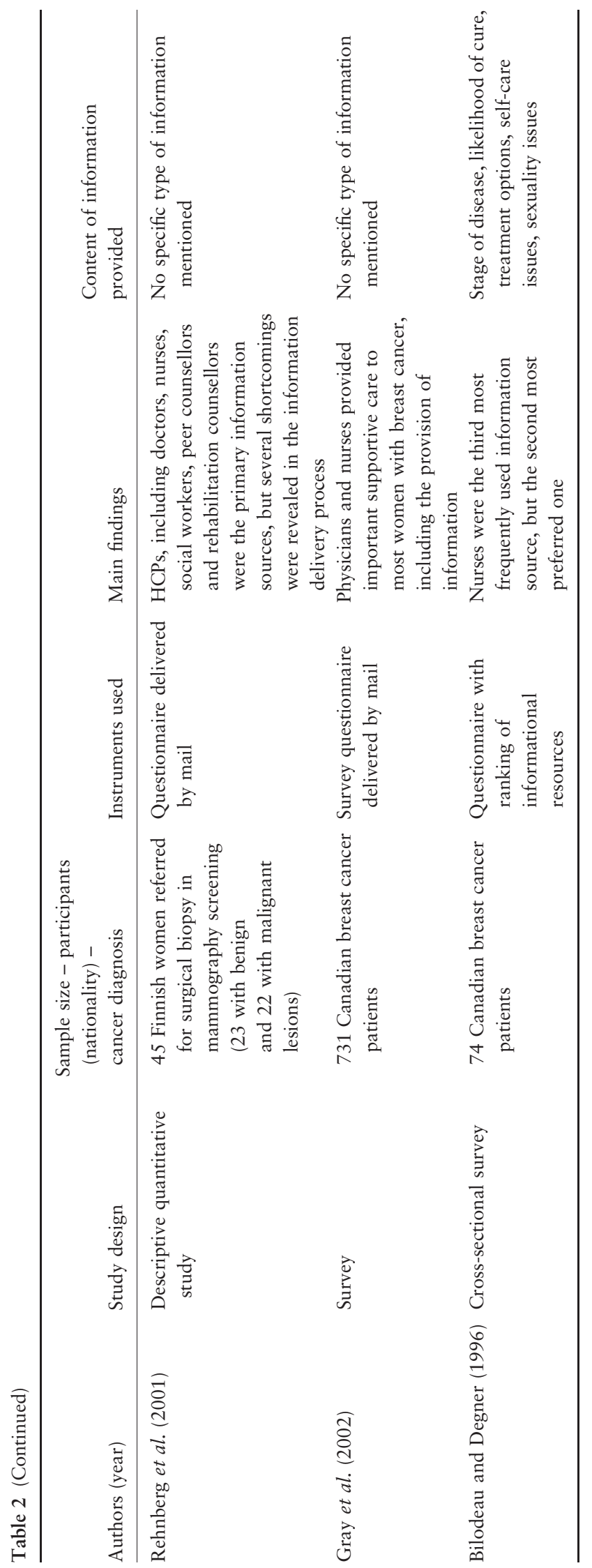

regarding the types of information provided precludes more specific conclusions (Table 1).

\section{Results referring to Advanced Nurse Practionners (APNs)/} Specialist Nurses

The observations reported by Booth et al. (2005) who conducted a prospective survey of 70 British patients with gynaecological cancer are worth noticing. Those participants, who were supported and informed by a nurse specialist, reported fewer worries six months from diagnosis. Most of the participants in the study preferred clinical nurse specialists as information and support sources. The most important patients' concerns involved questions regarding the current illness, the future, treatment issues, the physical symptoms and 'being able to do things'. In a study undertaken in Ireland by Mills and Davidson (2002), with 430 cancer patients who were asked to rate 19 commonly available sources of information, Specialist/Macmillan nurses were the preferred source of information for the majority patients and they were rated the highest in terms of quality of information. However, the most frequently cited source of information was the hospital consultant, with nurses being at the fourth position as ward staff. These results are in accordance with those by Luker et al. (2000) who conducted a mixed methods qualitative and quantitative study. More specifically, breast care cancer nurses were perceived more knowledgeable and qualified to provide information than the primary health care team. The types of information required were not mentioned specifically.

The findings summarised below involve either clinical nurse specialists or nurse practitioners. Hallowell (2000), in a qualitative study involving 23 British women undergoing prophylactic oophorectomy, concluded that patients should have access to gynaecology nurse specialists both before and after surgery to receive information related to oophorectomy and associated after-effects. Similarly, in an Australian study, Raupach and Hiller (2002) reported that women undergoing primary treatment for breast cancer received decreasing amounts of information about treatment, recurrence and risk to family members further on from the time of diagnosis. In a UK study of 105 breast cancer patients (Luker et al. 1996), the breast care nurse specialist was considered as a very useful source of information by $80 \%$ of participants, being preceded only by the hospital consultant $(95 \%)$. Ward and clinic nurses were identified as sources of information by $37 \%$ of participants compared to those who received information by general practitioners $(25 \%)$. Further, in a British qualitative study on the experiences of patients with operable esophageal cancer, although the surgeon and other patients were identified as key sources 
of information, the need for nurses specialised in thoracic surgery was emphasised (Mills \& Sullivan 2000). In a retrospective descriptive study of satisfaction with supportive care in Swedish patients with upper gastrointestinal cancers, patients reported that the information given by the specialist nurse was easier to understand and that they found it easier to put questions to nurses than to physicians. Nonetheless, these differences were not statistically significant (Viklund et al. 2006). Likewise, in a qualitative British study (Chapple et al. 2006), palliative care patients valued information on practical matters provided by specialist nurses, which is in agreement with results in Australian breast cancer patients (Halkett et al. 2006).

Several studies emphasise the advanced knowledge and the specialised competencies of APNs in assessing and responding to the informational needs of individuals with cancer (Wolf 2004a, Raja Gopal et al. 2005). In a qualitative UK study, it was found that breast care nurses assessed patient-centred concerns in addition to the provision of standard information, whereas surgeons offered only factual details about surgery (Wolf 2004b). Accordingly, in a Canadian study, the informational needs of 97 women at high-risk for breast cancer were met by nurse specialists with a high level of satisfaction (Stacey et al. 2002). The most important information needs identified were personal risk factors, breast cancer screening and lifestyle options. Koinberg et al. (2002), in a phenomenographic study in Sweden, reported that breast cancer patients' satisfaction with check-up visits to a specialist nurse was high. They were very satisfied with the knowledge and skills of the specialist nurses who provided them with the suitable amount of information including selfcare education and breast self-examination.

The above studies suggest that APN/specialist nurses are vital in providing information to cancer patients. They are commonly identified as primary sources of information, however, not as frequently as physicians. Based on the studies reviewed, it could be inferred that nurses may provide information of different type and content and, presumably, in a different manner than physicians and other HCPs. The specific content, quality and means of information delivery by specialist nurses were not always made explicit.

\section{Studies not distinguishing specifically nurses' role from that of other HCPs}

Based on such studies one can only infer the role of nurses since they refer to nurses in general and only in one, APNs are specifically mentioned. Some investigators referred to an 'assisting' nursing role in information delivery, usually complementary to the medical role. Others referred to the informational role of the therapeutic team, through inclusive terms such as 'HCPs', 'hospital staff', or 'medical staff' and they did not differentiate nurses' input from that of others HCPs.

The results of an exploratory qualitative study with breast cancer reconstruction patients conducted in the USA, supported that information was sought from several sources, however, the most important sources of information were the plastic surgeon and other physicians (Neill et al. 1998). The type of information provided included treatment options and the decision-making process. These results were consistent with those of several recent studies, which explored information needs and information giving (Meredith et al. 1996, Silliman et al. 1998).

Chelf et al. (2002) studied 625 adult cancer patients in the USA and reported that patients preferred interactive, interpersonal communication with physicians or nurses. Patients desired accurate information about issues including treatment, diagnosis, side-effects management, coping strategies and nutrition. In support of these results, several studies concluded that individuals with cancer prefer mostly HCPs as information providers (Veronesi et al. 1999, Hope et al. 2000, Kyngäs et al. 2001, Stewart et al. 2000, Rehnberg et al. 2001, Montazeri et al. 2002).

Similarly, in a qualitative study exploring the nature of stressors in 12 Icelandic women during the diagnostic phase of breast cancer, participants related that they sought detailed and honest informational support first and foremost from HCPs and that they were satisfied with the information received from them (Fridfinnsdottir 1997). This finding is consistent with the results of others who reported that most of the patients are satisfied with the information provided by HCPs (Carlsson 2000, Kyngäs et al. 2001, Leydon et al. 2000, Gray et al. 2002). However, Kerr et al. (2003), in a prospective observational study with breast cancer patients in Germany, reported that the information received from physicians was perceived as unclear, incomprehensible and incomplete by patients, who wished to have more time to speak with medical staff. In line with these, in a British study, cancer patients reported that they often received insufficient information (Cox et al. 2006).

In a Canadian study with women completing treatment for breast cancer, nurses were pointed out as the most important information source after the oncologist and more frequently than the family doctor (Edgar et al. 2000). In another Canadian study (Bilodeau \& Degner 1996), 74 women ranked nurses as being their third most frequent source of information, after physicians and family or friends and the most preferred information source after physicians. The investigators concluded that patient's informational needs were unmet by nurses. 
Nonetheless, HCPs are not always the preferred information providers and other kinds of information resources have been reported. Several investigators reported that individuals with cancer may prefer informal sources of information such as other patients, media, friends and relatives (Griffiths \& Leek 1995, Luker et al. 1996, Shingler et al. 1997, Davison et al. 2003). Similarly, in the USA, a qualitative study highlighted that although patients sought information from a variety of sources, one of the most common and helpful sources of information was other patients who had had similar experiences (Skalla et al. 2004). Such observations may raise concerns about the quality, efficacy and appropriateness of the information delivery by HCPs.

\section{Discussion}

This review attempted to delineate the degree and effectiveness of nurses' input into the provision of treatment- and disease-specific information to individuals with cancer. The most important findings were: (1) nurses' role as information providers for cancer patients is prominent, especially after the initiation of treatment, (2) specialist nurses are very effective in providing information, (3) no clear evidence exists on how nurses compare to other physicians and social workers as information providers and (4) some evidence exists that patients may prefer nurses as information providers at specific times in their treatment and especially in regards with symptom management.

The limitations of this review stem mainly from the diversity of studies synthesised regarding:

- the diversity in the categories of oncology nurses (i.e. APNs, staff nurses, specialist nurses),

- the different countries of origin, since discrepant delineations of nurses' roles may exist and

- the different settings. Studies carried out in oncology vs. general hospitals may yield discrepant results due to differences in the background, education and roles of nurses. Additionally, studies lacked a common definition of information delivery and the specific types of information delivered and/or requested were not always clarified.

Provision of information is regarded as an essential part of patient education, which may also have an impact on patient outcomes (Veronesi et al. 1999) and satisfaction with care (Koinberg et al. 2002, Stacey et al. 2002). Although the information delivery by nurses has been explored in several studies, the lack of a universal definition and the vagueness regarding the specific contents and means of information delivery renders the extraction of definite conclusions difficult. Moreover, given the methodology of the studies reviewed, the effectiveness and quality of nurses' input can only be inferred based on patients' reports. It would be desirable to be able to discern any potential effects of nurses' information delivery on the clinical outcomes and satisfaction of individual patients. Nurses provide information as part of a therapeutic plan, based on the assumption that they may enhance individuals' potential for recovery and well-being. However, this hypothesis, although highly relevant to the premises of 'therapeutic nursing' and of evidence-based practice, has not been addressed in the studies reviewed.

Most of the existing literature and almost all of the studies reported in this review originated from North American, Australian, Canadian or UK health care systems. There is limited research evidence relating to the provision of information for individuals with cancer in other countries. A possible reason is that information delivery is directly involved with truth-telling practices. Significant cultural influences on the attitudes of nurses caring for cancer patients may shape their professional values and communication/ information delivery practices. For example, in Hellas and in other Mediterranean or Eastern countries, HCPs face several difficulties in their day-to-day communication with cancer patients (Vinton 2001, Mystakidou et al. 2004). As a consequence of cultural and role barriers, there is a lack of evidence regarding nurses' role in the information providing process. Moreover, in countries where nurses experience low professional autonomy, such as in Hellas, provision of information may not be regarded as a nursing role (Papathanassoglou et al. 2005). Given the medical-dominance in health-care in some countries, involvement of nurses with the information delivery process may be regarded as threatening to the power-balance of the health-care system (Patiraki 2003). Another possible explanation for the paucity of studies in countries with cultures other than the Anglo-Saxonic may be that advanced nursing roles are not fully developed in most European and Eastern countries (Kearney 2000). In Europe, educational criteria for advanced practice have not been defined. Consequently, the educational preparation of nurses working in advanced practice roles is variable, sporadic, limited and even non existent (Richardson et al. 2000). For example, in Hellas it was just in 2003 that a two-year programme for a master's degree in oncology nursing and palliative care was developed by the School of Nursing of the University of Athens, whereas in the USA and throughout the UK the number of APNs providing cancer care nursing has increased progressively over the last years (Hill 2000, Murphy-Ende 2002). Moreover, language remains a major barrier for implementing research findings and for publishing nursing research conducted in non-English speaking countries (Patiraki et al. 2004).

However, several conclusions can be drawn from these studies. First, information was portrayed as a very 
individualised part of care and, at the same time, nurses appeared to be regarded by patients as having both the opportunity and the competence to provide appropriate and individualised information. Individuals can cope better with their health problems when they are provided with information that is accurate, relevant to their situation and considered important by themselves (Harrison et al. 1999). Although nurses may be assumed to possess some essential skills for effective communication and successful provision of information, the particular skills involved, along with the means to teach and to develop them remain to be corroborated by specific research evidence.

As reviewed earlier, patients with cancer frequently rely on their physicians to inform them about their medical care. On the other hand, nurses are seen as a key source of information, especially by the end of treatment, presumably due to the increased contact with cancer patients and the shift of the information needs of patients towards self-care and issues of daily activities. Clearly, nurses who have the longest exposure to individuals with cancer are an obvious and easily accessible source of information. Nonetheless, there is no evidence regarding either the amount of time that nurses may spent on information-giving, or the type of patients' concerns and queries that may be addressed to nurses more frequently than to doctors. Although not concretely supported by evidence, it is presumable that, without the nursing participation, many patients would not correctly comprehend the information provided by their physicians, regarding their diagnosis, prognosis and treatment options and that this could affect their decision-making process negatively. Repetition of explicit information, given in everyday language was found essential in helping cancer patients to cope with illness and its uncertainty (Van Der Molen 1999). However, although we are inclined to presume that oncology nurses can enhance patient knowledge by translating information about the illness and its outcomes, their methods of patient assessment and the means and strategy of information giving are unclear. Based on the lack of pertinent evidence, one may conclude that probably, with the exception of specialists, the majority of nurses employ an intuitive rather than a systematic approach for the delivery of information, the content of which varies according to the specific patient needs and queries. Another important finding was that, overall, specialist nurses are perceived as being very skillful and effective in the provision of information. This is corroborated by international findings that the role of specialist breast care nurses is perceived as very important by patients throughout the trajectory of their care (Halkett et al. 2006). Based on such evidence, it is reasonable to promote the development of diverse specialist cancer care nursing roles, both in Anglo-Saxon countries that may have already embraced specialist nursing roles, as well as in the rest of the world.

\section{Relevance to clinical practice}

The results of this review indicated that cancer patients have strong preferences for interpersonal sources of information, such as nurses. Therefore, nurses should be specifically educated and prepared to offer explicit, practical and timely information. Moreover, it appears important that nurses are trained in interpersonal communication skills, which will increase their ability to comprehend patient information needs, to perceive the barriers of communication and to intervene appropriately. Oncology nurses should be accessible to provide individualised information of desirable amount during their daily clinical practice to cancer patients. Additionally, nurses can assist individuals to access information using methods they feel comfortable with, such as Internet sources, books and periodicals, as they have the knowledge and skills to assess the appropriateness of such educational materials and to offer guidance. However, for nurses to realise their important educational role, nursing management support is required. In many countries, nurses may need to be empowered to extend their practice and to claim and develop patient education practices. Since provision of information to individuals with cancer is intertwined with truth-telling practices, clinicians may need to reflect on interrelated issues such as cultural directives, attitudes and patients' rights to develop appropriate and effective plans for the delivery of information.

\section{Conclusion}

Nurses are seen as a key source of information during and by the end of treatment. More research is needed to elucidate the specific contents of information delivered by nurses and the communication means and skills employed.

\section{Implications for research}

The effectiveness of oncology nurses as information providers to patients with cancer still requires study. The major and crucial role of nurses as information providers seems underrepresented in the nursing literature. It could be argued that the above findings are neither representative of, nor transferable to different cultures and countries. Thus, more nursing research is needed to explore the information provision process in countries and cultures of non Anglo-Saxon origin. Future research needs to address the type of patient queries that are 
addressed to nursing, the content of the information provided and the practical means and interpersonal skills employed.

It is important to address any potential effects of nurses' provision of information on cancer patients' psychological and physiological outcomes, as well as on patients' satisfaction with care and quality of life. These may be explored through either standard experimental designs or through interpretive modes of investigation.

\section{Contributions}

Study design: EIP, SK, EP; data collection and analysis: EP, SK, MK and manuscript preparation: EP, SK, EIP.

\section{References}

Benner P (1984) From Novice to Expert. Excellence and Power in Clinical Nursing Practice. Addison-Wesley, Menlo Park, CA.

Bilodeau BA \& Degner LF (1996) Information needs, sources of information and decisional roles in women with breast cancer. Oncology Nursing Forum 23, 691-696.

Booth K, Beaver K, Kitchener H, O’Neill J \& Farrell C (2005) Women's experiences of information, psychological distress and worry after treatment for gynaecological cancer. Patient Education and Counseling 56, 225-232.

Brown M, Koch T \& Webb C (2000) Information needs of women with non-invasive breast cancer. Journal of Clinical Nursing 9, 713-722.

Carlsson M (2000) Cancer patients seeking information from sources outside the health care system. Supportive Care in Cancer 8, 453457.

Chapple A, Ziebland S \& McPherson A (2006) The specialist palliative care nurse: a qualitative study of the patients' perspective. International Journal of Nursing Studies 43, 1011-1022.

Chelf JH, Agre P, Axelrod A, Cheney L, Cole DD, Conrad K, Hooper S, Liu I, Mercurio A, Stepan K, Villejo L \& Weaver C (2001) Cancer-related patient education: an overview of the last decade of evaluation and research. Oncology Nursing Forum 28, 11391147.

Chelf JH, Deshler AMB, Thiemann KMB, Dose AM, Quella SK \& Hillman S (2002) Learning and support preferences of adult patients with cancer at a comprehensive cancer center. Oncology Nursing Forum 29, 863-867.

Cox A, Jenkins V, Catt S, Langridge C \& Fallowfield L (2006) Information needs and experiences: an audit of UK cancer patients. European Journal of Oncology Nursing 10, 263-272.

Davies E \& Higginson IJ (2003) Communication, information and support for adults with malignant cerebral glioma: a systematic literature review. Supportive Care in Cancer 11, 21-29.

Davison BJ, Goldenberg SL, Gleave ME \& Degner LF (2003) Provision of individualized information to men and their partners to facilitate treatment decision making in prostate cancer. Oncology Nursing Forum 30, 107-114.

Davison BJ, Keyes M, Elliott S, Berkowitz J \& Goldenberg SL (2004) Preferences for sexual information resources in patients treated for early-stage prostate cancer with either radical prostatectomy or brachytherapy. BJU International 93, 965-969.

Deane KA \& Degner LF (1998) Information needs, uncertainty and anxiety in women who had a breast biopsy with benign outcome. Cancer Nursing 21, 117-126.

Echlin KN \& Rees CE (2002) Information needs and informationseeking behaviors of men with prostate cancer and their partners: a review of the literature. Cancer Nursing 25, 35-41.

Edgar L, Remmer J, Rosberger Z \& Fournier MA (2000) Resource use in women completing treatment for breast cancer. PsychoOncology 9, 428-438.

Flanagan J \& Holmes S (2000) Social perceptions of cancer and their impacts: implications for nursing practice arising from the literature. Journal of Advanced Nursing 32, 740-749.

Fridfinnsdottir EB (1997) Icelandic women's identifications of stressors and social support during the diagnostic phase of breast cancer. Journal of Advanced Nursing 25, 526-531.

Friis LS, Elverdam B \& Schmidt KG (2003) The patient's perpespective: a qualitative study of acute myeloid leukaemia patients' need for information and their information-seeking behaviour. Supportive Care in Cancer 11, 162-170.

Gray RE, Fitch M, Greenberg M, Hampson A, Doherty M \& Labrecque M (1998) The information needs of well, longer-term survivors of breast cancer. Patient Education and Counseling 33, 245-255.

Gray RE, Goel V, Fitch MI, Franssen E \& Labrecque M (2002) Supportive care provided by physicians and nurses to women with breast cancer: results from a population-based survey. Supportive Care in Cancer 10, 647-652.

Griffiths M \& Leek C (1995) Patient education needs: opinions of oncology nurses and their patients. Oncology Nursing Forum 22, 139-144.

Halkett G, Arbon P, Scutter S \& Borg M (2006) The role of the breast care nurse during treatment for early breast cancer: the patient's perspective. Contemporary Nurse 23, 46-57.

Hallowell N (2000) A qualitative study of the information needs of high-risk women undergoing prophylactic oophorectomy. PsychoOncology 9, 486-495.

Harrison DE, Galloway S, Graydon J, Palmer-Wichkam S \& Rich-van der Bij L (1999) Information needs and preference for information of women with breast cancer over a first course of radiation therapy. Patient Education and Counseling 38, 217225 .

Hill A (2000) The impact of expanding the numbers of clinical nurse specialists in cancer care: A United Kingdom case study. European Journal of Oncology Nursing 4, 219-226.

Hinds C, Streater A \& Mood D (1995) Functions and preferred methods of receiving information related to radiotherapy. Perceptions of patients with cancer. Cancer Nursing 18, 374-384.

Hope S, Williams AE \& Lunn D (2000) Information provision to cancer patients: a practical example of identifying the need for changes in practice from the Dorset Cancer Centre. European Journal of Cancer Care 9, 238-242.

Johnson JE, Fieler VK, Jones LS, Wlasowitcz GS \& Mitchell L (1997) Self-regulation Theory: Applying Theory to Your Practice. Oncology Nursing Press, Pittsburgh.

Kearney N (2000) Nursing education in cancer care. In Cancer Nursing Practice. A Textbook for the Specialist Nurse (Kearney N, 
Richardson A \& Di Giulio P eds). Churchill Livingstone, London, pp. 91-106.

Kerr J, Engel J, Schlesinger-Raab A, Sauer H \& Hölzel D (2003) Communication, quality of life and age: results of a 5-year prospective study in breast cancer patients. Annals of Oncology 14, 421-427.

Koinberg I, Holmberg L \& Fridlund B (2002) Breast cancer patients' satisfaction with a spontaneous system of check-up visits to a specialist nurse. Scandinavian Journal of Caring Sciences 16, 209-215.

Kyngäs H, Mikkonen R, Nousiainen EM, Rytilahti M, Seppänen P, Vaattovaara R \& Jämsä I (2001) Coping with the onset of cancer: coping strategies and resources of young people with cancer. European Journal of Cancer 10, 6-11.

Lacey MD (2002) The experience of using decisional support aids by patients with breast cancer. Oncology Nursing Forum 29, 14911497.

Lauri S \& Sainio C (1998) Developing the nursing care of breast cancer patients: an action research approach. Journal of Clinical Nursing 7, 424-432.

Leydon GM, Boulton M, Moynihan C, Jones A, Mossman J, Boudioni M \& McPherson K (2000) Cancer patients' information needs and information seeking behaviour: in depth interview study. British Medical Journal 320, 909-913.

Liu J-E, Mok E \& Wong T (2006) Caring in nursing: investigating the meaning of caring from the perspective of cancer patients in Beijing, China. Journal of Clinical Nursing 15, 188-196.

Luker KA, Beaver K, Leinster SJ \& Glynn Owens R (1996) Information needs and sources of information for women with breast cancer: a follow-up study. Journal of Advanced Nursing 23, 487-495.

Luker KA, Beaver K, Austin L \& Leinster SJ (2000) An evaluation of information cards as means of improving communication between hospital and primary care for women with breast cancer. Journal of Advanced Nursing 31, 1174-1182.

Lundberg PC \& Trichorb K (2001) Thai Buddhist patients with cancer undergoing radiation therapy. Cancer Nursing 24, 469475.

Meredith C, Symonds P, Webster L, Lamont D, Pyper E, Gillis CR \& Followfield L (1996) Information needs of cancer patients in West Scotland: cross sectional survey of patients' views. British Medical Journal 313, 724-726.

Mills ME \& Davidson R (2002) Cancer patients' sources of information: use and quality issues. Psycho-Oncology 11, 371-378.

Mills ME \& Sullivan K (1999) The importance of information giving for patients newly diagnosed with cancer: a review of the literature. Journal of Clinical Nursing 8, 631-642.

Mills ME \& Sullivan K (2000) Patients with operable oesophageal cancer: their experience of information-giving in a regional thoracic unit. Journal of Clinical Nursing 9, 236-246.

Montazeri A, Vahdani M, Haji-Mahmoodi M, Jarvandi S \& Ebrahimi M (2002) Cancer patient education in Iran: a descriptive study. Supportive Care in Cancer 10, 169-173.

Murphy-Ende K (2002) Advanced practice nursing: reflections on the past, issues for the future. Oncology Nursing Forum 29, 106-112.

Mystakidou K, Parpa E, Tsilika E, Katsouda E \& Vlachos L (2004) Cancer information disclosure in different cultural contexts. Supportive Care in Cancer 12, 147-154.
Negrier S, Gomez F, Chauvin F, Buclon M, Syp L, Gonnon G, Dumortier A, Friedrich M \& Saltel P (2007) Treatment planning visit in oncology: factors predictive of satisfaction with the meeting with the physician and benefits of a second interview with a nurse. $\mathrm{La}$ Presse Médicale 36, 779-785.

Neill KM, Armstrong N \& Burnett CB (1998) Choosing reconstruction after mastectomy: a qualitative analysis. Oncology Nursing Forum 25, 743-750.

Papathanassoglou ED, Tseroni M, Karydaki A, Vazaiou G, Kassikou J \& Lavdaniti M (2005) Practice and clinical decision-making autonomy among Hellenic critical care nurses. Journal of Nursing Management 13, 154-164.

Patiraki E (2003) Greece. In Cultural Assessment, 3rd edn (Geissler EM \& Erickson D’Avanzo C eds). Mosby, New York, NY, pp. 303-307.

Patiraki E, Karlou C, Papadopoulou D, Spyridou A, Kouloukoura C, Bare E \& Herkouris A (2004) Barriers in implementing research findings in cancer care: the Greek registered nurses perceptions. European Journal of Oncology Nursing 8, 245-256.

Raja Gopal LR, Beaver K, Barnett T \& Nik Ismail NS (2005) A comparison of the information needs of women newly diagnosed with breast cancer in Malaysia and the United Kingdom. Cancer Nursing 28, 132-140.

Raupach JCA \& Hiller JE (2002) Information and support for women following the primary treatment of breast cancer. Health Expectations 5, 289-301.

Rees CE \& Bath PA (2000) The information needs and source preferences of women with breast cancer and their family members: a review of the literature published between 1988 and 1998 . Journal of Advanced Nursing 31, 833-841.

Rehnberg G, Absetz P \& Aro AR (2001) Women's satisfaction with information at breast biopsy in breast cancer screening. Patient Education and Counseling 42, 1-8.

Richardson A, Di Giulio P \& Waddell D (2000) Nursing research in cancer care. In Cancer Nursing Practice. A textbook for the Specialist Nurse (Kearney N, Richardson A \& Di Giulio P eds). Churchill Livingstone, London, pp. 107-134.

Rutten LJ, Arora NK, Bakos AD, Aziz N \& Rowland J (2005) Information needs and sources of information among cancer patients: a systematic review of research (1980-2003). Patient Education and Counseling 57, 250-261.

Sainio C \& Eriksson E (2003) Keeping cancer patients informed: a challenge for nursing. European Journal of Oncology Nursing 7, 39-49.

Semple CJ \& MCGowan B (2002) Need for appropriate written information for patients, with particular reference to head and neck cancer. Journal of Clinical Nursing 11, 585-593.

Shingler G, Balusu R \& Thomas R (1997) Where do patients seek additional information after a diagnosis of cancer: a multicentre survey? European Journal of Cancer 33, S321.

Silliman RA, Dukes KA, Sullivan LM \& Kaplan SH (1998) Breast cancer care in older women. Sources of information, social support and emotional health outcomes. Cancer 83, 706-711.

Skalla KA, Bakitas M, Furstenberg CT, Ahles T \& Henderson JV (2004) Patients' need for information about cancer therapy. Oncology Nursing Forum 31, 313-319.

Stacey D, DeGrasse C \& Johnston L (2002) Addressing the support needs of women at high risk for breast cancer: evidence-based care 
by Advanced Practice Nurses. Oncology Nursing Forum 29, E77E84.

Stewart DE, Wong F, Cheung AM, Dancey J, Meana M \& Cameron JL, M'Andrews MP, Bunston T, Murphy J \& Rosen B (2000) Information needs and decisional preferences among women with ovarian cancer. Gynecologic Oncology 77, 357-361.

Van Der Molen B (1999) Relating information needs to the cancer experience: 1. information as a key coping strategy. European Journal of Cancer Care 8, 238-244.

Veronesi U, von Kleist S, Redmond K, Costa A, Delvaux N \& Freilich G, Glans A, Hudson T, McVie JG, MacNamara C, Meienier F, Pecorelli S \& Serin D (1999) Caring about women and cancer (CAWAC): a European survey of the perspectives and experiences of women with female cancers. European Journal of Cancer 35, 1667-1675.
Viklund P, Wengström Y \& Lagergren J (2006) Supportive care for patients with oesophageal and other upper gastrointestinal cancers: the role of a specialist nurse in the team. European Journal of Oncology Nursing 10, 353-363.

Vinton N (2001) Ethnicity and Cancer Patient Information. National Cancer Alliance; Retrieved September, 2001 from the World Wide Web: http://www.teamworkfile.org.uk/download/TW2\%20S\%20 Asian\%20Lit\%Review.pdf.

Wolf L (2004a) The information needs of women who have undergone breast reconstruction. Part I: decision-making and sources of information. European Journal of Oncology Nursing 8, 211-223.

Wolf L (2004b) The information needs of women who have undergone breast reconstruction. Part II: information giving and content of information. European Journal of Oncology Nursing 8, 315-324. 